\title{
PANORAMA DE LA FISCALIZACIÓN PARLAMENTARIA HACIA FINES DEL SIGLO XX
}

\begin{abstract}
Alan Bronfman Vargas ${ }^{1}$
SUMARIO: Introducción. Los matices de una crisis general. La fiscalización en los parlamentos modernos. El control en asambleas que imitan los modelos británico y norteamericano. La situación del control en los parlamentos racionalizados o disminuidos. Perspectivas para fortalecer la labor fiscalizadora. Bibliografía.
\end{abstract}

\section{INTRODUCCION}

Hemos adquirido el hábito de pensar en el parlamento como una institución en retirada. Tanto hemos leído y escuchado de su edad de oro, su declive, la necesidad de reformarlo, revitalizarlo, modernizarlo, que nos parece natural pensar que permanecerá donde está por muchos años. Sin querer tendemos a considerarlo un antiguo convidado de piedra del régimen constitucional y por eso solemos ser indiferentes ante el traspaso de sus funciones a los medios de comunicación social, al Ejecutivo o a sus agentes, al Poder Judicial, e incluso a órganos internacionales. El problema es que, mientras no se cree algo mejor, el parlamento sigue siendo la institución más adecuada para acoger la representación política y para el ejercicio de la funciones legislativa y de control. Nuestro propósito en las líneas que siguen es explicar, de modo sucinto, las condiciones de ejercicio de la fiscalización parlamentaria en algunas asambleas americanas y europeas, para mostrar que es una tarea que, pese a sus dificultades, puede ser realizada bien por la institución. Hacia el final, esbozaremos algunas de los reformas que se han promovido para hacer más efectivo su ejercicio.

Para escribir acerca del control parlamentario en general es necesario formular algunas distinciones. Para ello utilizaremos una clasificación que se apoya en la historia y la tradición de cada asamblea. Si bien ella omite aspectos que podrían hacerla más completa - y también más compleja-, la entendemos útil para resaltar que el estado actual de la cuestión exhibe significativas diferencias según el país de que se trate.

La clasificación es particularmente necesaria en la medida que el diagnóstico generalizado de debilidad del parlamento tiende a obscurecer las diferencias entre instituciones muy disímiles, lo que sin duda perjudica la búsqueda de soluciones a

\footnotetext{
Doctor en Derecho por la Universidad de Santiago de Compostela, Profesor de Derecho Constitucional en las Universidades Católica de Valparaiso y de Valparaiso.
} 
los obstáculos que enfrenta la labor fiscalizadora. Lo cierto es que sin perjuicio de algunos elementos comunes, la realidad de cada parlamento es única y por ende cualquier análisis del funcionamiento institucional exige identificar el origen y alcance de sus problemas.

Antes de comenzar, tenemos que dedicar unas palabras a explicar lo que entendemos por control parlamentario, por cuanto sostenemos una noción quizás más amplia que la tradicional. Fiscalización parlamentaria es, para nosotros, el examen de la actividad de gobierno realizado por el parlamento y caracterizado por la publicidad del procedimiento y por su especial influencia política. Es decir, el examen público y la influencia política son los elementos constitutivos del control, sin ser especialmente relevante, para estos efectos, la forma competencial que sirva para materializarlo.

Es menester agregar que se trata de una función que, dentro del sistema político, sólo puede asumir el parlamento. Ninguna otra institución puede reemplazar la actividad fiscalizadora que realiza el parlamento, pese a que las apariencias sugieran otra $\operatorname{cosa}^{2}$. Mientras no se creen nuevas instituciones políticas, el perfeccionamiento de la democracia exige impulsar el fortalecimiento de la función fiscalizadora, pues constituye una de las vías para enriquecer los contenidos de la representación política.

\section{LOS MATICES DE UNA CRISIS GENERAL}

En nuestra opinión, hacia fines del siglo XX, la tradicional idea de una crisis general de la institución parlamentaria debe ser revaluada. Por lo pronto, porque es una idea algo antigua formulada en directo contraste con un tipo de asambleas las liberales clásicas sin partidos disciplinados- que dejaron de existir hacia fines del siglo $\mathrm{XIX}^{3}$. Ya ha pasado demasiada agua bajo el puente para seguir empleando unos parámetros decimonónicos que no tienen relación con la realidad política actual. Por cierto que las asambleas democráticas que surgen con el sufragio universal emprenden un camino que las aleja del modelo liberal, pero esto no

\footnotetext{
2

Por cjemplo, se ha transformado en un tópico afirmar que parte de la función de control público es realizada por los medios de comuncación. Esta idea es crrónea, pues no sabemos cuáles son las motivaciones que impuls'n las denominadas "imvestigaciones perindísticas", ni su alcance, rigor, profundidad y objetivos. Muchas de ellas son deliberadamente parciales y obedecen a intereses concretos que se ocultan bajo una proclamada neutralidad. En el parlamento todos estos elementos están sobre la mesa y no bajo ella.

3 I'ue lowell, en 1896, uno de los primeros que observó que los parlamentes estaban dejando de ser importantes. Para quien recién empezaba a conocer el funcionamiento parlamentario de un nuevo tipo de partidos parecia natural entender al parlamento como un poder público en decadencia o que, en el mejor de los casos, habia perdido mucho de lo que tenia. Lin todo caso fue Lord Bryce el que popularizó la expresión "el declive de las legislaturas", a partir de un capitulo asi titulado de su obra Modem Democraciex. En su argumentación, una buena parte de los males son atribuidos a los cambios en el régimen representativo y a los rasgos de los nuevos partidos políticos (disciplina, parlamentarios "empleados", etc.), y otro tanto a cuestiones propiamente parlamentarias (BRYCl., I ord, "I he decline of legislatures" en NORTON, Philip (ed.), Legishlatures, Oxford, Oxford UP, 1992, 47-56, 55-56).
} 
significa que estén condenadas a carecer de importancia dentro del sistema político. Como bien explica Wheare en Legislatures, tenemos que emplear otra mirada para comprender el funcionamiento de las asambleas contemporáneas, ya que el desarrollo de los partidos políticos y los cambios en el gobierno, la sociedad y la economia han modificado de manera profunda los equilibrios constitucionales de antaño ${ }^{4}$.

Y no sólo debemos acomodar nuestro punto de vista y expectativas generales. Como señalamos antes, la posición política y constitucional de cada parlamento americano y europeo es diferente $y$, por ende, cualquier juicio acerca de su funcionamiento actual y posibilidades futuras exige distinguir si pretendemos añadir algo a las críticas conocidas. De ahí que sea conveniente emplear la clasificación que anunciamos al comienzo para efectos de analizar las condiciones de ejercicio del control parlamentario. Ella divide a los parlamentos europeos y americanos en tres grandes categorías, agrupando aquellos que tienen una evolución histórica similar y disfrutan de una posición institucional equiparable en sus respectivos sistemas políticos.

En la primera categoria incluimos a las asambleas que podemos considerar modélicas para el parlamentarismo y el presidencialismo, a saber, la británica y la norteamericana. Creemos que el principal rasgo de estas asambleas es que su participación en la función de gobierno, sea a través de la función legislativa, presupuestaria o de control, es principal e incuestionada ${ }^{5}$. Un Primer Ministro o un Presidente norteamericano, por ejemplo, no intentarían violar una convención asentada por la historia de las relaciones Ejecutivo-Legislativo, pues tal conducta podría poner en peligro su cargo. En el mismo sentido, es evidente que la posición constitucional de estos parlamentos no suele cambiar como consecuencia un resultado electoral concreto.

El Parlamento británico, pese a los esfuerzos del gobierno laborista por someter y mermar su fuerza, mantiene una enorme influencia política y social ${ }^{6}$. Como dijimos, ella no puede ser desconocida y tiene especial importancia como apoyo de la función fiscalizadora. Por su parte, el Congreso Federal norteamericano y las cincuenta asambleas de los estados miembros conservan su autoridad política, cualesquiera sean las mayorías dominantes en una u otra rama, mediante el ejercicio

\footnotetext{
${ }^{4}$ WIILARE, Kenneth C., Legislatures, Londres, Oxford University Press, 1963, 119 y ss,

${ }^{5}$ Con un matiz: el Congreso Ficderal interviene a la creación de politicas públiças; la Cámara de los Comuncs más bien revisa y perfecciona las iniciativas del Gobierno.

El escalo de dirección política de los nuevos laboristas y su lider Tony Blair es, de manera notoria, más rígido que el de sus predecesores. Sin duda, el control sobre los miembros del partido es más estricto que en el pasado. En la misma linea, los nuevos laboristas, rompiendo con tradiciones seculares, están promoviendo reformas al estilo continental, la mayoria de las cuales propicia una disminución de los poderes del parlamento. Ejemplos de esta actitud son la reforma del régimen electoral (materializada ya en la elección proporcional de parlamentarios curopeos) y los cambios en la composición de la Cámara de los l.ores.
} 
de la funciones legislativa y presupuestaria?. El Ejecutivo debe negociar con los congresales proyectos de ley y para ello debe dar explicaciones acerca de su conducta pasada y futura. Lo mismo puede decirse de los presupuestos, cuya aprobacicin de ordinario genera un intenso debate y un ulterior riguroso control de ejecución.

En una segunda categoría es posible incluir a los parlamentos que con algún éxito intentan seguir los modelos británico y norteamericano. Caben aquí algunas de las asambleas de los países miembros de la Commonvealth o bajo influencia británica. También algunos parlamentos americanos que disfrutan de una historia institucional relativamente larga (al menos centenaria) y que siguen, en mayor o menor medida, el modelo norteamericano. Un lugar destacado cabe aquí a la Asamblea Legislativa costarricense que funciona hace más de ciento setenta años en el marco de un sistema institucional estable". Algo parecido puede decirse del Poder Legislativo de Uruguay que realiza su labor desde 1828, con algunas interrupciones de importancia ${ }^{10}$. También el Congreso chileno acumula una experiencia institucional nada desdeñable desde $1830^{11}$. Estas asambleas tienen tras de si una historia que les permite gozar de una posición institucional sólida, incuestionable, pese a los embates y ambiciones del gobierno y los partidos políticos. La configuración constitucional, legal y reglamentaria de este segundo tipo de asambleas suele asegurar a los parlamentarios una influencia política considerable. Además el poder del parlamento en estos países puede llegar a reforzarse de manera significativa si se produce una coyuntura política favorable.

\footnotetext{
7 No obstante, en alguna medida los term limits y los procedimientos legislativos populares han dañade la posición política de las asambleas en los estados miembros.

${ }^{8}$ A modo de ejemplo, Canadá y Australia. También podrian incluirse en esta categoria algunos parlamentos del continente 9 como el sueco o el danés, cuya evolución los ha llevado a soluciones similares a las de Westminster

131 proceso de emancipación de la corona española comienza en 1821, aunque sólo en 1838 Costa Rica se separa de la Federación Centroamericana. El quiebre más significativo en su funcionamiento se produce durante la Guerra Civil de 1948. L.a Asamblea Legislativa celcbra ya su 82 legislatura. Sobre su influencia política entre los años 1958-1970, vide Hugutes, Steven y Mijeski, Kenneth, Legiskatir-Evocuthe Polig-Making. The Cases of Chile and Casta Riza, Beverly Hills, Sage, $1973,27-48$.

Entre 1828 y 1900 corren setenta y dos años, de los cuales en catorce d legislativo no pudo funcionar (1838-1839. 1846-1852, 1853-1854, 1865-1868, 1876-1879, 1898-1899). Pérez. Antón estima que entre 1830 y 1890 el Congreso estuvo sometido al Poder Ejecutivo (PÉREZ ANTÓN, Romeo, "Poder Legislativo y ordenamiento constitucional: el case uruguayo" en CABALliero Carrizosa, Esteban y Vial., Alejandro (eds.), Poder Legilativo en el Cono Sur, vol. I, Asunción. Centro de Estudios Democráticos, 1994, 112-113). Para el mismo autor el protagonismo politico del Congreso comienza en la última década del siglo XIX Como es sabido, durante el siglo XX vanas legislaturas son interrumpidas por intervenciones militares (1933-1934, 1942, 1973-1985). Ën todo caso, la tradición democrática uruguaya parece muy bien aserntada.

11 Los órganos internos del propio Congreso fijan el nacimiento antes (lo que puede verse, por ejemplo, en la conmemoración de ciento ochenta años de evolución institucional). No obstante, es probable que la verdadera continuidad histỏnca soblo pueda seguirse hasta la asamblea constituida en 18280 al Congreso posterior al triunfo conservador de 1830. Hay algunas interrupciones en sus sesiones regulares (1890, 1930), pero la única importante parece ser la que corresponde al periodo 1973-1990.
} 
En este bloque también podemos incluir parlamentos como el brasileño, el colombiano y el argentino, pese a que es muy difícil dimensionar el éxito institucional de órganos cuya vida se ha desarrollado entre clausuras, intervenciones militares y conflictos políticos muy intensos. El Congreso brasileño, por ejemplo, tuvo una participación relevante en el ejercicio del poder federal entre 1840 y 1930 , para después sufrir diversos embates que incluyen un cierre (durante el estado novo, 1937-1945) y un régimen de tutela militar entre 1964 y $1985^{12}$. Alguna doctrina sostiene un juicio negativo acerca de la influencia del Congreso en el sistema político, que contrasta con su capacidad de sobrevivir en circunstancias en extremo adversas ${ }^{13}$.

En el caso argentino, el Congreso federal ha debido soportar condiciones todavía más adversas. El período de funcionamiento democrático más largo, excluido el que comienza en 1983, se remonta a los años 1916-1930. La relativa debilidad de la asamblea, se explica entonces por las "sucesivas y prolongadas interrupciones que los gobiernos militares impusieron a la vida de los partidos y al funcionamiento del Parlamento" ${ }^{14}$. Estas interrupciones, impidieron que el

12

En el periodo 1840-1889 ya disfrutaba de potestades de peso que ejercía regularmente, incluida la de censurar al gobierno. Se trata de una censura que ponía en jucgo una de las dos caras de la confianza del gabinete (que también existía en varios parlamentarismos continentales europeos en la primera mitad del siglo XIX). La otra eonfianza dependia del emperador, que también distrutaba de la facultad de disolver la Cámara, despuês de oír al Consejo de Estado y convocar a nuevas elecciones. Fil sistema permitia la alternancia de los dos principales partidos, por lo que se aceptaba como una buena solución, pese a la alta rotación ministerial (treinta y seis gabinetes en cincuenta años). Durante la Primera República (1890-1930), el Congreso mantuvo su influencia, aunque el poder efectivo en la Unión dependia de las oligarquias politicas dominantes en los estados (São Paulo, Minas Gerais, Rio Grande do Sul). Sin embargo, en 1930 se produce una revolución que de manera paulatina daña los intereses del Congreso. inicia una serię de reformas. La Carta de 1934 incluyó, por ejemplo, representación parlamentaria al modo corporativista, modelo empleado primero en Italia y luego en paises como Portugal c Irlanda, La instauración del esfado norv (1937-1945). La Constitución de 1937 disolvió el Parlamento, las asambleas estaduales y las cámaras municipales, ordenando su elección después de un plebiscito constitucional. Ėste nunca se realizó por lo que el Presidente Getulio Vargas pudo gobernar durante todo cl eslado norv a través de decretos-leyes. Fntre 1945 y 1964 el Congreso vuelve a funcionar con esporádicas interrupciones de la normalidad constitucional. Como solución a un problema de sucesión presidencial cl Congreso aprobó en 1961 el cambio del régimen presidencialista por uno parlamentarista. La reforma fue sometida a plebiscito en 1963, en el que triunfó el presidencialismo. En 1964, un golpe militar acaba con el régímen democrático, aunque permite la subsistencia de un parlamento tutelado hasta el fin del gobierno militar en 1985. En este parlamento, la no tramitación de leyes propuestas por el Ejecutivo dentro de plazo, significaba su aprobación tácita. Además, el Ejecutivo podía revocar los mandates parlamentarios y no se reconocian las tradicionales inmunidades parlamentarias. Cfr. FAUSTO, Boris, História do Brasil, São Paulo, Fditora da Unuversidade de São Paulo-Fundação para o Desenvolvimento da Educação, $2001\left(9^{a}\right.$, ed.), passim.

13

BMAkilNi, Abdo, "Legislative Reforms in the Brazilian Chamber of Deputies 1964-1975" en BAMLINI, Abdo y IIEAPHEY, James, Comparatie I egzlative Reforms and Innorations, Albany, Comparative Development Studies Center-State University of New York, 1977.259.

14

THWatifs ReY, Mabel, "Apuntes para pensar la modernización del Parlamento argentino" en Primer Congreso Internacional de Modernización Parlamentaria, Documentos y Conchusiones, 'Tomo II, Bucnos Aires, Congreso de la Nación Argentina, 1991, 541. Según Molinelli, la ctapa más regular en el funcionamiento del Congreso federal, excluida la actual, se produce entre los años 1890 y 1904 en cuanto a frecuencia anual, duración y continuidad de las sesiones (MoI.INFI.f., Guillermo, "Una cronologia de los periodos de sesiones del Congreso argentino (1854-1986)" en Reristu de Deretho Parlamentano 3, Buenos Aires, Dirección de Información Parlamentaria-Cámara de Diputados, 1091, 69). El mismo autor sostiene que a partir de 1912 el funcionamiento del Congreso genera una imagen de "irregularidad e imprevisibilidad" (MOtINEt.t., op. cit. 70, 78-79). Hay quiebres cntre 1930-1931, 1942-1946, 1955, 1961-1963, 1966$1973,1975-1982$ 
Congreso se convirtiese en un lugar de negociación política y que desarrollase su capacidad técnica y política para ejercer las funciones legislativa y de control. En Colombia, la introducción del sufragio universal no produjo un cambio significativo en el sistema formal de partidos políticos, que se mantuvo inalterado bien hasta avanzado el siglo XX. Esta situación, si bien compatible con una estabilidad formal y con el funcionamiento regular de la asamblea, ha dificultado la convivencia pacífica y la vigencia efectiva del régimen constitucional.

En una tercera categoría ubicamos a los parlamentos cuya distancia con los arquetipos británico y norteamericano es mayor, tanto por razones jurídicas como políticas. En este grupo, es probable que la Asamblea Nacional francesa represente el criterio constitucional más alejado del modelo británico, rasgo que en alguna medida se transmite a los parlamentos europeos cuya configuración replica la respuesta gaullista a los problemas de la III y IV Repúblicas. Caben aquí los parlamentos "racionalizados" que Europa ha creado en sus constituciones y que carecen de una tradición histórica que sirva de contrapeso al robustecimiento de los partidos iniciado con el sufragio universal ${ }^{15}$.

Por otras razones, pueden considerarse también incluidas dentro de este grupo de asambleas disminuidas, una parte importante de los parlamentos de regímenes presidencialistas iberoamericanos. Reunimos aquí a aquellos que se alejan del modelo norteamericano como consecuencia de unas condiciones políticas y económicas poco estables, apoyadas por la creciente influencia de modelos continentales europeos ${ }^{16}$.

El principal rasgo de las asambleas que incluimos en esta categoría son las restricciones impuestas a sus competencias. Las limitaciones surgen por la vía de imponer condiciones especiales para el ejercicio de competencias (v. gr. censura constructiva, quórums reforzados) o bien por la desprotección de la institución frente a los fuertes intereses de los partidos políticos o del Ejecutivo. Su grado de participación en la actividad legislativa y de control depende de factores políticos, a veces simplemente coyunturales, ya que la formalización jurídica de sus atribuciones alcanza sólo a sus potestades básicas ${ }^{17}$. En este tipo de asambleas, no hay, o son escasas y febles, las convenciones que incrementan el poder del parlamento.

\footnotetext{
15

La expresión "racionalización" empleada por la doctrina (y hasta por la jurisprudencia) sugiere maliciosamente la irracionalidad de las asambleas no sometidas a ella. Hay que notar que tal irracionalidad, si existe, deriva en última instancia del carácter democrático de la representación parlamentaria. El ongen de la expresión se encuentra en la obra de Boris MIRKINE. GUETZEVTTCH Ies nomelles rendances du dmit constitutionnel de 1931. Antes CARRE DE MAl.BERG utilizó para el mismo fin la vo2 "parlamentarismo relativo". En 1958, JANOT se refirió al "parlamentarismo depurado" para aludir a la misma situación (TURPIN, Dominique, Le régime purlementuire, Paris, Dalloz, 1997, 65).

16

Ascendiente que parece acrecentarse durante el último cuarto del siglo XX. Vide, por ejemplo, las reformas a fa 17 Constitución argentina đe 1994, o las nuevas Constituciones colombiana y paraguaya.

En el caso de Italia, por ejemplo, ha sido un factor político - la reçurrente fragmentación de la representación parlamentaria - el que ha otorgado un especial peso a las funciones legislativa y de control desarrolladas por ambas cámaras. Las que han empleado mecanismos reglamentarios como el orden del dia y el voto secreto para asegurar su
} 


\section{LA FISCALIZACIÓN EN LOS PARLAMENTOS MODELOS}

Hecha la distinción anterior, podemos intentar presentar un panorama de las condiciones de ejercicio de la función de control en algunos parlamentos americanos y de Europa occidental.

En el Parlamento más antiguo del mundo, la función de control conserva su vitalidad e incluso, en algunas materias, parece robustecerse. La fiscalización de Westminster sigue siendo intensa en el pleno: el Primer Ministro y sus colaboradores directos deben concurrir casi todas las semanas ante los Comunes y explicar sus decisiones. Las respuestas reciben una difusión pública amplia, en especial si la comparamos con la realidad de otros países del continente. Además, iniciativas como el Next Step o la reforma de los Select Committee, aunque controvertidas en sus resultados, demuestran que existe preocupación por intentar mejorar la actividad fiscalizadora del Parlamento ${ }^{18}$. Por otra parte, los esfuerzos del gobierno laborista por disciplinar a sus parlamentarios y disminuir la influencia de los Lores (o al menos convertirla en un apoyo), demuestran, de manera indirecta, que la institución sigue siendo una pieza básica para el ejercicio de la función de gobierno.

Como es lógico, existen problemas que amenazan el control parlamentario de Westminster. Éstos son viejos y nuevos. Son viejos aquellos que surgen de los intentos de fortalecer la disciplina partidista, para lograr una acción cohesionada y una imagen electoral unitaria. Los partidos disciplinados tienden a destruir la vida parlamentaria, en tanto la someten a unos intereses políticos que funcionan como mandatos rígidos. Un cierto grado de indisciplina, sobre todo en el partido de gobierno, es un buen abono para el crecimiento de la actividad parlamentaria ${ }^{19}$.

Son nuevos aquellos que provienen de la entrega de competencias a Bruselas, que aunque lenta y cauta, merma la tradicional capacidad de la Cámara de los Comunes de vigilat toda la actividad de Gobierno. También la globalización parece estar afectando el punto de vista de la clase política británica —o de al menos parte de ella-, que está dando por buenas instituciones constitucionales y legales de

influencia politica (Della Sala, Vincent, "The Italian Parliament: Chambers in a Crumbling House" en Norton, Philip, Parliaments and Governments in Western Lurope, Londres, Frank Cass, 1998, 73-96)

18

El programa Next Step intentó aumentar los cargos públicos responsables ante el parlamento, modificando la tradicional doctrina que concentra toda la responsabilidad política en los miembros del gabinete (PYPER, Robert, "Ministerial Responsability and Next Steps Agencies" en GidDings, Philip (ed), Parliamentary Aconntability, Hampshire, Macmillan Press, 1995, 19-32). La reforma de los Select Committee, criticada por muchos, parece haber enriquecido la actividad fiscalizadora agregando funciones que en el pasado no eran desarrolladas por el Parlamento (NORTON, Philip, "Nascent Institutionalisation: Committees in the British Parliament" en LONGI.FY, Lawrence y DAvIDSON, Roger, The New Roles of Purliumentany Cammit/ees, Londres, Frank Cass, 1998, 145 y 159; GRIFTTH, J.A.G.; RYI.E, Michacl; WIIEIJ.ER-BOOTH, 19 M.A.J., Partiament: Functions, Practice and Procedteres, Londres, Sweet \& Maxwell, 1997 (reimpresión), 421).

En Inglaterra se admite que una buena parte del trabajo parlamentario se dedique a perseguir el apoyo de los propios miembros del partido. Este es el sentido de la opinión de un vicjo parlamentario, que hizo salir de su error a un nuevo colega que, con ingenuidad, pensaba que sus adversarios estaban sentados al frente. 
origen continental, cuya superioridad sobre las antiguas disposiciones británicas parece más teórica que práctica ${ }^{20}$.

En los Estados Unidos, el Congreso Federal es un órgano de control especialmente activo a través de dos competencias, la legislativa y la presupuestaria. En la mayoría de los parlamentos europeos y americanos, la primera en el mejor de los casos, se encuentra sometida a negociación entre los principales partidos. La segunda suele estar dominada por los intereses gubernamentales. La fiscalización en Norteamérica es apoyada por un régimen electoral y de financiación de campañas que robustece el vínculo representativo y que hace muy difícil concentrar el poder dentro de los partidos. Asimismo, la separación de poderes característica del presidencialismo admite la elección cámaras dominadas por mayorías adversas al Presidente, posibilidad estimulada por el sistema de renovación de los miembros del Congreso Federal.

La labor del Congreso Federal ofrece muchos aspectos criticables por la opinión pública y es posible que algunas de sus facultades de control sufran daño como consecuencia de esta vulnerabilidad. La lentitud y complejidad de los procedimientos del Congreso no encaja bien en una sociedad acostumbrada a vincular eficiencia y tiempo, aun cuando muchos reconozcan que la eficiencia política puede revestir formas caóticas. En todo caso, la reducción de las potestades de control, de producirse, vendría por la vía de limitar la influencia política de los parlamentarios y no por el camino de reformar atribuciones concretas. En el nivel estadual, los term limits, por ejemplo, imponen una barrera infranqueable a la carrera política de parlamentarios, medida que disminuye la dotación de experiencia política que la institución requiere para fiscalizar. Del mismo modo, el incremento de los procedimientos populares para la aprobación y derogación de leyes conlleva, en la práctica, una merma en la influencia política de las asambleas norteamericanas.

También podría afectar la capacidad fiscalizadora del Congreso la crítica que se dirige al gasto público en órganos de asesoría. La Congressional Budget Office, el Congressional Research Service, la General Accounting Office y el personal al servicio de ambas cámaras, comisiones, representantes y senadores, sumados constituyen una organización competente para apoyar el desarrollo de la función representativa, aunque muy costosa. La reducción presupuestaria de esta asesoría podría mermar la capacidad de análisis del Congreso, mientras que el Ejecutivo conserva su amplio

\footnotetext{
20) Ya mencionamos ejecplos de este cambio de mentalidad: la reforma del sistema clectoral aplicable a las elecciones del Parlamento curopeo y la inconclusa modificación de la Cámara de los Lores que, por cl momento ha tenido el único éfecto de disminuir la influencia conservadora en la Cäman Alta. También se formó una comisión especializada, presidida por lord Jenkins, para estudiar la reforma del sistema mayoritario. Su informe sugiere introducir un sistema de voto alternativo (alfernative tofe ples) que incrementa el porcentaje de votos que cada candidato elegido obtiene en su distrito y otorga una cicrfa cuota de representación proporcional calculada sobre una base regional. lo significativo de la reforma propuesta es que no modifica el elemente central del sistema, los distritos uninominales, respetando en este sentido la exigencia del Primer Ministro relativa a la obligación de preservar el vinculo entre los miembros del parlamento y sus clectores
} 
aparato técnico. Como sea, en los Estados Unidos los principales peligros para el control no provienen de los partidos políticos, sino más bien de otros agentes del sistema: la burocracia, el ejecutivo y el poder económico.

\section{EL CONTROL EN ASAMBLEAS QUE IMITAN LOS MODELOS BRITÁNICO Y NORTEAMERICANO}

Aunque ya describimos los rasgos de esta categoría, parece conveniente intentar ser un poco más precisos en su caracterización. En el campo de los parlamentarismos, nos estamos refiriendo a asambleas que disfrutan de una posición relativamente fuerte dentro de su sistema político, por distintas razones. Puede ser, por ejemplo, que su régimen electoral tenga rasgos mayoritarios y permita establecer una relación directa entre el parlamentario y sus votantes. $O$ bien, puede que sus facultades no estén disminuidas por procedimientos agravados $y$ en su funcionamiento interno no existan prerrogativas extraordinarias para los representantes del Gobierno. Como indicamos arriba, podemos incluir en esta categoría a los parlamentos de Canadá y Australia, y a los de otras antiguas colonias británicas. Caben también los de Suecia y Dinamarca, e instituciones jóvenes como el Parlamento escocés o el galés.

En la mayoría de estas asambleas las atribuciones de control son, por el momento, suficientes. En el campo del control ordinario, es muy fuerte la actividad fiscalizadora a través de preguntas o comparecencias. En esta materia, el modelo del question time británico ha sido imitado, dando lugar a un regular y saludable examen de la gestión del gobierno. En varias de estas asambleas, el avance en la tecnología de comunicaciones permite generar una amplia oferta para el ciudadano que pretende conocer la actividad fiscalizadora ${ }^{21}$.

En el campo del control extraordinario, mantienen su importancia las comisiones de investigación, aunque todavía no existen respuestas satisfactorias frente al predominio de una mayoría progubernamental en su seno ${ }^{22}$. Por otra parte, el mecanismo de la censura, salvo supuestos precisos (como el de una coalición débil o un partido poco cohesionado), tiene escasa aplicación práctica, por lo que no podemos considerarlo como una competencia fiscalizadora relevante ${ }^{23}$.

\footnotetext{
${ }^{21}$ Por ejemplo, a través de redes informáticas o señales propias de radio o televisión (como el C-SPAN norteamcricano). Con todo, es claro que la abundante oferta de información parlamentaria no sirve para combatir la extendida apatía civica.

22

Aun en paises que permiten su constitución por decisión de una minoria, como Alemania o Portugal. Tratándose de una función que debiera carecer de la impronta partidista, no parece una mala alternativa su designación por sorteo, al modo de la comisión de estudio de la acusación constitucional que se forma en nuestra Cámara de Diputados. 2.3

Es evidente que la censura ha perdido su importancia con el surgimiento de los partidos disciplinados. En Gran Bretaña, por ejemplo, en el siglo XX sólo tres gobiemos han cesado por derrotas parlamentarias (BIRCH, Anthony, The Britib System of Gomernment, Londres, Routledge, 1993 (9a ed.), 169-171). En Irlanda, el Dail ha hecho caer al gobierno sólo en dos ocasiones, en noviembre de 1982 y de 1992 (O'HALPIN, Eunan, "A Changing Relationship? Parliament and Government in Ireland" en NORTON, Philip, Parliaments and Cotemments in W'estem Europe, Londres, Frank Cass, 1998,
} 
Los parlamentos que disponen de una estructura jurídica de este tipo debieran buscar nuevas vías para incrementar su control sobre el ejecutivo. Por lo pronto, la censura individual, todavía poco difundida como mecanismo formal, debiera ser la norma en una época caracterizada por gobiernos sobreprotegidos política y constitucionalmente. Lo anterior, se entiende, en la medida que no se sufran graves problemas de inestabilidad. Incluso la innovadora idea del programa Next Step de agregar nuevos cargos responsables ante el parlamento, no parece del todo errada, pues introduce flexibilidad en un modelo de responsabilidad solidaria que sólo admite como sanción la destitución de todo el gabinete. También el sistema de comisiones debiera ser perfeccionado, por ejemplo, por medio de una disposición que asegure la celebración de sesiones públicas de control.

Las asambleas del tipo que venimos comentando se enfrentan a peligros similares a los explicados antes. El fortalecimiento de la disciplina de partido y, en el caso de los parlamentos europeos, el traspaso de competencias a la Unión Europea, pueden mermar su capacidad de control. También la aparente $-y$ publicitada - función fiscalizadora que realizan los medios de comunicación social puede tener un efecto negativo, especialmente en la medida que el parlamento comienza a ser presentado, por contraste, como una mera caja de resonancia para la exagerada dialéctica de los políticos. Por cierto que un medio de comunicación imparcial podría servir de apoyo a la función de control, pero lo normal será que su sometimiento a intereses empresariales y unas técnicas periodísticas hagan que tal contribución sea resultado del azar.

En el presidencialismo, la situación del control en las asambleas más próximas al modelo norteamericano no es mala. La vigencia del principio de separación de poderes, permite que el ejecutivo y la asamblea no compartan siempre los mismos intereses políticos, lo que favorece la fiscalización. En países como Chile, por ejemplo, el Presidente tradicionalmente ha tenido que ejercer su mandato en pugna con una de las dos ramas del Congreso dominadas por la oposición ${ }^{24}$. Sin duda, la ausencia de mayorías de un mismo partido o coalición en ambas cámaras es un buen punto de partida para el control sobre el gobierno.

\footnotetext{
126). In Italia desde 1947 hasta 1987, dos gobiernos han sido derrotados por via de moción de no confianza. lin Francia, la censura también ha sido un mecanismo casi no utilizado, ya que desde 1958 hasta junio de 2001, únicamente ha tenido éxito la votada el 5 de octubre de 1962 contra Georges Pompidou (PACrET, Pierre, Institutions politiques. Druit constitutionnel, Paris, Armand Colin, 1999 (18 ed, actualizada hasta agosto de 1999), 453). En Alemania se han interpuesto sólo dos censuras desde la aprobación de la Constatución hasta la fecha, triunfando una de ellas, la de 1982 contra Schmidt (MenY, Yves, Gotemment and Politics in Weatern Eumope, Oxford, Oxford UP, 1993 (2 ed.), 216-218).

Y en los escasos periodos en que no ha sido asi, ha tenido que lidiar con los parlamentarios de la propia coalición gubernamental. Cfr. VALENZUELA, Arturo, "Partidos políticos y crisis presidencial en Chile: proposición para un gobicrnes parlamentario" en GoDOY ARCAY.A, Oscar (ed.), Hacia una democracia moderna. La opción purlamentaria, Santiago, lidiciones Universidad Católica, 1990, 165-171 y 181; y NOGueirA AlCALÁ, Humberto, Análisis crilico del prisidencialismo y consideraciones solme una allernatina de rigimen-semipresidencial para Chrle, Santiago, Instituto Chileno de Estudios Ifumanisticos, 1986, 47-49.
} 
En el régimen presidencialista los mecanismos de control más empleados no son los del parlamentarismo. El ejecutivo da explicaciones, pero no en la forma ni con el sentido electoral que encontramos en el parlamentarismo. Por lo común, el presidente que pretende avanzar en su programa legislativo o lograr la aprobación de su ley de presupuestos debe convencer a sus propias fuerzas parlamentarias y, eventualmente, conquistar los votos de independientes e incluso de la oposición. Entonces pueden presentarse explicaciones (o si se quiere, argumentaciones), pero éstas se dirigen a unos congresales o líderes políticos y no necesariamente al pleno de la cámara y a los ciudadanos. El manejo de la agenda y, sobre todo, la iniciativa legislativa, corresponde al ejecutivo, aunque esta ventaja se encuentra en parte neutralizada por la necesidad de lograr el asentimiento de la mayoría parlamentaria para la aprobación de leyes ofrecidas en el programa electoral. El Presidente puede emplear las explicaciones públicas acerca de su gestión o decisiones para generar apoyo a sus pretensiones en el parlamento, pero no es necesario que realice esta labor a través de los procedimientos de control. Por otra parte, el control presupuestario tiende a conservar su importancia, pese a los esfuerzos del ejecutivo por minimizar el alcance del examen parlamentario ${ }^{25}$.

Además de los mecanismos anteriores, las asambleas de este tipo suelen tener facultades fiscalizadoras para solicitar información al gobierno acerca de diversos aspectos de su gestión. A diferencia de lo que sucede en los parlamentarismos, el ordenamiento jurídico no dispone la comparecencia regular de miembros del gabinete, aunque no es rara su participación en diversos procedimientos parlamentarios ${ }^{26}$. En algunos de las asambleas del tipo que venimos comentando, existen mecanismos que permitirian forzar la comparecencia de miembros del gabinete, aunque en la práctica no han sido utilizados de manera regular para tal fin ${ }^{27}$.

\footnotetext{
25

En Chile cfr. TAPIA VALDÉs, Jorge, "Funciones y atribuciones del parlamento entre 1960 y 1990 " en BERTLISEN

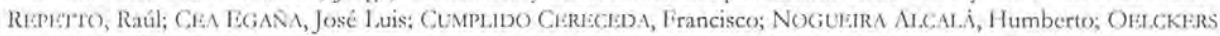

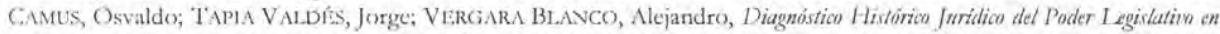
Chile 1960-1990, Valparaiso, Centro de Listudios y Asistencia Legislativa Universidad Católica de Valparaiso, 1993, 106-

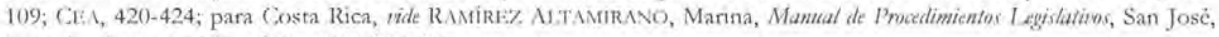
Investigaciones juridicas S.A., 1994, 231-242.

${ }^{26}$ Por ejemplo, comparecencias para presentar o defender proyectos de ley impulsados por el ejecutivo.

2)

Nos referimos a la censura. En Uruguay desde 19.34 existen procedimientos de desaprobación de la conducta politica de ministros o de todo el Conscjo de Ministros. Pese a que la censura sólo ha sido aplicada en una ocasión (en 1969), alguna doctrina sosticne que ha inducido una colaboración más estrecha entre ejecutivo y legislativo (PÉREZ ANIÓN, op. cit., 117). En Costa Rica los ministros pueden ser interpelados o censumdos por la Asamblea legislativa, pero la aprobación de tales instrumentos, por los dos tercios de los diputados, no acarrea su destitución, ni afecta su responsabilidad política. Se trata más bien de una sanción moral que, de todos modos, podría materializarse en una renuncia o remoción dispuesta por el Presidente (RAmirF.Z, op. cit, 369-370). El mecanismo no se acomerda bien a los presidencialismos (y como vimos, tampoco a los parlamentarismos contemporancos). Si el ejecutivo tiene mayoria en el parlamento, lo usual será que no se emplee, salvo que los liderazgos del partido o coalición sean distintos en ambos poderes, por el contrario, si la oposición tiene mayoria puede bloquear al ejecutivo censurando a todos sus gabinetes, impidiéndole realizar su programa de gobierno. En esta segunda hipótesis es válido preguntar quién gobierna. 1ista fuc una de las cucstiones que dilucidó la revolución de $1891 \mathrm{en}$ Chile.
} 
A los instrumentos ordinarios de control, debemos agregar competencias fiscalizadoras extraordinarias, que pueden tener especial relevancia en asuntos políticos de considerable incidencia electoral. Nos referimos, fundamentalmente, a las comisiones de investigación y al juicio político. Las comisiones de investigación, a diferencia de lo que acaece en los regímenes parlamentaristas, no siempre son controladas por una mayoría pro-gubernamental. Esta circunstancia propicia que los partidos de gobierno (o serios aspirantes al poder) establezcan y defiendan restricciones a sus competencias, o bien, subrepticiamente, levanten obstáculos políticos para hacer más dificil el avance de la investigación. En sistemas electorales mayoritarios, la cobertura de los medios de comunicación suele ser un estímulo para que los miembros de la comisión realicen una labor investigadora seria o, al menos, vistosa. En sistemas electorales proporcionales, la mayor influencia de los partidos puede apagar la vida de la comisión o convertirla en una mero escenario para la representación de la tradicional confrontación entre gobierno y oposición.

El juicio político, descendiente presidencialista del impeachment británico, conserva su relevancia como mecanismo fiscalizador ${ }^{2 \mathrm{~g}}$. Al igual que la censura, el juicio político puede ser emprendido como un simple instrumento para concitar el interés público cuando se carece de las mayorías necesarias para aprobarlo ${ }^{29}$. Sin duda, la posibilidad de iniciarlo en contra de altas magistraturas sin afectar la responsabilidad política del órgano (salvo en el caso del Presidente) puede constituir una ventaja respecto del modelo de responsabilidad típico del parlamentarismo.

Las asambleas presidencialistas que hemos incluido en esta segunda categoría también pueden sufrir la merma de sus facultades fiscalizadoras. Como siempre, el fortalecimiento de la disciplina partidista puede afectar el ejercicio del control, aunque la clara separación de la carrera parlamentaria y la carrera dentro del gobierno tiende a poner un límite a la influencia de los partidos. Otro peligro es el crecimiento de las organizaciones paraestatales y el desarrollo de la gestión pública a través de concesiones u otras fórmulas, que alejan de la mirada parlamentaria cuestiones de innegable interés social. Subrayemos que la denominada huida del

\footnotetext{
28

1. a historia del impeachment comicnæa a gestarse cuando los Lores abandonan su función de tribunal de primera instancia y se reservan el conocimiento de acusaciones contra lores o comunes iniciadas por estos últimos. Lista actuación comenzó a ser conocida como impeachment y su primer cjercicio, reconocido como tal, es el dirigido contra lord l.atimer en el Good Parliament de 1376 (MAIn.AND, F.W., The Constitutional I listary of England, Cambridge, Cambridge University Press, 1926, 215). La incipiente institución dejó de utilizarse en 1459, por su negativa interpretación politica y por la relativa debilidad del Parlamento. Reapareció en 1621, ya con un nuevo sentido. La formulación en este año de un impeachment contra un ministro del Rey inició un nuevo periodo, en el que se fueron asentando con precisión las causas que permitian el inicio del procedimiento. En èl, los comunes actuaban como informadores, fiscales y miembros de un gran jurado, y los Lores cumplian la función de alta corte de justicia y de jurado, conociendo y jưgando los cargos 29 presentados (Young, Roland, The Britisb Parliument, Fvanston, Northwestern University Press, 1962, 183-184).

Aunque los caminos para su triunfo no están siempre cerrados (como ocurre en la mayoría de los regímenes parlamentaristas).
} 
Derecho público, un fenómeno que también se observa en los países europeos, es propiciada por las nuevas demandas de la actividad económica.

Asimismo el incremento de las facultades legislativas $y$ normativas del presidente puede considerarse una amenaza para la función fiscalizadora. Además de la común vigencia de procedimientos excepcionales para la aprobación de normas generales, no es raro encontrar privilegios que aseguran la tramitación acelerada de proyectos de interés para el ejecutivo ${ }^{30}$.

\section{LA SITUACIÓN DEL CONTROL EN LOS PARLAMENTOS RACIONALIZADOS O DISMINUIDOS}

En la tercera y última categoría incluimos a los parlamentos cuya estructura jurídica y realidad política impide realizar una labor de control efectiva. Se trata de asambleas que sufren variadas carencias: no se apoyan en un sistema electoral acorde con las necesidades de la representación parlamentaria, no cuentan con atribuciones suficientes para realizar una fiscalización intensa, forman parte de un sistema político inestable, etc. En la mayoría de los casos, el control parlamentario funciona de manera tardía, empujado por la propia fuerza de los hechos, aportando poco o nada al sistema político. De manera excepcional, en determinadas coyunturas políticas (v. gr. acefalía del ejecutivo, derrumbe de partidos tradicionales, amenaza de intervención militar), el parlamento puede ejercer un control más intenso y tener una influencia electoral significativa.

En los países europeos encontramos varias asambleas de este tipo. La Asamblea Nacional francesa, por ejemplo, tiene pocas posibilidades de fortalecerse por el conjunto de restricciones constitucionales que se imponen a su organización y funcionamiento ${ }^{31}$. En este sentido, de poco sirve el desarrollo institucional si no existe la posibilidad de franquear unas rígidas disposiciones que traban el funcionamiento parlamentario. Algo parecido puede sostenerse en el caso del Congreso de los Diputados español, que une a los males de la "racionalización", un sistema electoral que favorece en exceso el control partidista sobre los parlamentarios.

\footnotetext{
30 Nos referimos a la declaración de urgencia, que obliga a tramitar determinados proyectos en periodos breves (v. grt. treinta dias). Fiste tipo de procedimicnto existe, por cjemplo, en Chile y Unguay, y es empleado con cierta frecuencia.

Regulación constitucional de la organizaciỏn interna (número fijo de comisiones, discusión en el pleno del proyecto del gobierner y no del informe de la comisión), dominio máximo legal, procedimientos de aprobación tácita de normas (si no se produce una censura dentro de plazo), revisión de los reglamentos por un órgano externo, etc. Con todo, de manera lenta, se van dejando atrás los rígidos moldes impuestos en 1958 mediante interpretaciones y prácricas, éstas últimas no siempre amparadas por la normativa. Cfr. SHAw, Malcolm, "Parliamentary Committees: A Global Perspective" cn LONGLeY, Lawrence D. y DAvidson, Roger H., The New Roles of Parliamentary Committeer, lirank Cass, 1998, 225-251, 232; Cilagnolland y QUermonNe, Dominique y QUeRmonne, Jean-Louis, Le gouremement de la France sous la Ve. Réprblique, Paris, Fayard, 1996 (nueva ed.), 445-446; РАCTET, op. cit-, 481-495.
} 
Por lo regular, la fiscalización más importante de estos parlamentos es la que se realiza mediante preguntas, interpelaciones y comparecencias. En este sentido, podemos observar que aún en los parlamentos europeos más débiles el question time se consolida lentamente como un procedimiento ordinario. Este tipo de control, pese a las limitaciones que suele sufrir (por ejemplo, en relación con antelación de las preguntas), tiene un efecto directo sobre el electorado y de ahí que su importancia no pueda desdeñarse.

No puede decirse lo mismo de otros medios de examen parlamentario. Las comisiones de investigación no han dado buenos resultados, en términos generales, porque el control de los partidos sobre los parlamentarios hace muy difícil el avance efectivo de la investigación. La ausencia de un vínculo representativo fuerte, sumada al predominio de una mayoría favorable al gobierno y a la presencia de una oposición que tiene como única meta descubrir responsabilidades políticas mayores, hacen que los fines naturales de la investigación queden hundidos en un mar de intereses partidistas.

Del mismo modo, como señalamos antes, la moción de censura ha perdido importancia como respaldo del control, salvo en el supuesto de determinados resultados electorales. También puede llegar a tener relevancia como instrumento para despertar el interés de los medios de comunicación social, cuando otras vías de control están cerradas ${ }^{32}$.

Las dificultades que amenazan el control de las asambleas que incluimos en esta tercera categoría son similares a las comentadas antes, aunque más graves. El poderoso control partidista sobre la actividad parlamentaria está cimentado en un marco normativo favorable a los intereses de los partidos, lo que crea una situación muy difícil de revertir. El problema puede ser todavía más serio, cuando la influencia de los partidos se extiende sobre gran parte de la organización social, ya que entonces la reforma del sistema exige un esfuerzo todavía mayor. Además, en algunos parlamentarismos, la larga ausencia de un control efectivo ha adormecido el sentido de la responsabilidad política, permitiendo al ejecutivo eludir fácilmente el deber de dar cuenta pública de sus actos. La misma ausencia ha servido para estimular un espejismo de fiscalización a través de los medios de comunicación social.

El futuro del control, en estas asambleas, depende de una competencia electoral que debiera propender al enriquecimiento de la relación representativa y ésta, al fortalecimiento de la institución parlamentaria.

\footnotetext{
32 El interés de los medios de comunicación, como bien saben los parlamentarios, se puede suscitar por otras vias menos onerosas. La censura es útil como "aviso" institucional de un partido o bloque de partidos, más que como reclamo publicitario de un parlamentano individual Con todo, en paises con censura constructiva (Alemania, Bélgica, España, Papủa Nueva Guinea), una censura nacida para fracasar puede ser útil para presentar a la comunidad las virtudes de un candidato alternativo a la iefatura de gobierno.
} 
Como señalamos arriba, en los regímenes presidencialistas iberoamericanos también encontramos asambleas disminuidas. En la mayor parte de los casos, la debilidad arranca más de factores políticos que de factores jurídicos (como normas restrictivas de las potestades del parlamento). La inestabilidad que muchos sistemas políticos americanos han sufrido durante los siglos XIX y XX es un fenómeno general que afecta tanto a los poderes públicos como a los partidos y hasta el funcionamiento de la propia sociedad. En las últimas décadas, la relativa calma política ha propiciado la búsqueda de nuevos mecanismos constitucionales para incrementar el control del parlamento sobre el gobierno, pese a que el problema de tales asambleas no parece provenir de su configuración jurídica. Países como Perú, Colombia y Paraguay han añadido procedimientos parlamentaristas a su régimen presidencial, intentando subsanar deficiencias que no tienen relación estricta con las competencias de la asamblea ${ }^{33}$. En el futuro cabe esperar que el funcionamiento permanente de las instituciones democráticas permita afianzar y robustecer la labor fiscalizadora del parlamento.

\section{PERSPECTIVAS PARA FORTALECER LA LABOR FISCALIZADORA}

Nuestro intento de caracterizar las condiciones de ejercicio del control parlamentario en distintas asambleas europeas y americanas, carece de utilidad si pretendemos buscar una solución única a los problemas del control. Esto porque los males de cada parlamento han de ser combatidos con un conjunto de remedios especialmente adaptados a su realidad. No obstante, existen condiciones generales que, en cualquier contexto político y constitucional, debieran incidir de manera favorable en el ejercicio de la fiscalización parlamentaria. Tales condiciones generales se apoyan en normas que protegen la relación representativa, ponen fronteras a los partidos, aseguran la importancia del parlamentario individual y garantizan el control sobre el gobierno. De ahí que, sin perjuicio de las soluciones particulares para cada asamblea, podamos propugnar, a modo de vigorizante, reformas en cuatro ámbitos normativos decisivos para el funcionamiento del parlamento. El contenido concreto de tales reformas, su alcance y sentido, dependerá de la situación política y constitucional de la asamblea de que se trate.

El primero de estos ámbitos es el referido al régimen electoral y su importancia estriba en su aptitud para generar una relación representativa directa entre el parlamentario y sus electores. Si las normas electorales no estimulan este

\footnotetext{
La presencia de instituciones parlamentaristas en los presidencialismos iberoamericanos tiene un antecedente en las experiencias parlamentaristas de la segunda mitad del siglo XIX y comienzos del XX (por ejemplo, en Brasıl y Chile). La ausencia de una definición clara de ambos modelos hizo más sencillo el trasvase de instituciones. Procedimientos como la interpelación o incluso la censura pueden encontrarse en antiguas constituciones americanas (por cjemplo, la ya mencionada regulación uruguaya de 1934). En todo caso, en la mayoria de los sistemas politicos, los injertos no han tenido especial relevancia para el funcionamiento de la separación de poderes.
} 
vínculo, el parlamento pierde el elemento que lo distingue dentro del sistema politico.

El segundo es el que atañe a los partidos políticos. El funcionamiento democrático de los partidos es básico para lograr el nacimiento de una relación representativa entre el parlamentario y el elector. Los partidos tienen una natural tendencia a confiar poco en los parlamentos, pero la competencia por el voto popular suele obligarlos a ser más representativos, disminuyendo la influencia de las cúpulas de partido. De todos modos, podrían promoverse en esta materia, por vía legislativa, estímulos para alcanzar una mayor democracia interna. Podría, por ejemplo, apoyarse la celebración de primarias para la selección de candidatos, mediante recursos públicos o espacios gratuitos en los medios de comunicación estatales. En aquellos países en donde existe financiamiento público de los partidos, también podría desconcentrarse la asignación de fondos públicos, permitiendo a las divisiones territoriales del partido una cierta autonomía respecto de la directiva central.

El tercer ámbito es el de la organización interna de la asamblea. El parlamento puede llegar a ser fuerte si logra convertirse más en un órgano representativo de los ciudadanos que en un órgano representativo de los partidos. Para esto es menester confiar en los diputados individuales, o en el pleno, pero no en los partidos. Es conveniente entonces que los reglamentos camerales combatan la concentración de poder, evitando la intervención de los comités, fracciones o grupos parlamentarios en todos aquellos casos en que no sea estrictamente necesario.

El cuarto campo es el de las competencias fiscalizadoras. Ya hemos comentado algunos de los elementos que permitirian su perfeccionamiento. Aquí es menester distinguir entre parlamentarismo y presidencialismo, pese a que las atribuciones sean formalmente muy similares.

En el parlamentarismo, los instrumentos de control tradicionales son la censura, las comisiones de investigación, preguntas y comparecencias. En relación con la censura, es claro que la posibilidad de emplearla como medio para exigir la responsabilidad política es escasa. La política y los partidos no son los del siglo XIX, y de ahi que sea necesario pensar en reformas profundas para convertirla en un instrumento útil dentro del parlamentarismo. La eliminación de la constructividad, la rebaja que su quórum de aprobación, el establecimiento de censura individual, e incluso su ampliación a otros cargos con responsabilidad política, podrían constituir cambios acertados en este sentido.

En materia de comisiones de investigación, debiera ser posible asegurar unos mínimos derechos a los parlamentarios de oposición que las integran. Por lo pronto, como en Alemania o Portugal, parece conveniente otorgar a una minoría la posibilidad de crearlas. Esta solución, aunque conveniente, no elimina el control de la mayoría sobre la dirección y avance de la investigación y de ahí que sean 
necesarias disposiciones adicionales. Por ejemplo, parece acertado garantizar la publicidad de algunas de sus actuaciones, como por ejemplo, las sesiones en que recibe declaraciones. Asimismo, sería adecuado reconocer a los parlamentarios de oposición la facultad de solicitar comparecencias o informes, o al menos exigir su asentimiento para aprobar un programa mínimo de investigación.

Además de las comisiones de investigación, sería conveniente que los parlamentos desarrollasen un sistema de comisiones dinámico y fuerte, adaptado a las necesidades del control. Las comisiones, en la medida que tengan vida propia una mínima independencia respecto de los partidos políticos - pueden contribuir a desconcentrar el poder político dentro del parlamento, lo que permite enriquecer el ejercicio de la función representativa. Cuando los diputados representan a sus votantes, surge la posibilidad de alejarse de los intereses de partido y lograr acuerdos políticos que permitan el buen funcionamiento de la comisión. Notemos que la relación directa con los ciudadanos es la que permite entender la autonomía de las comisiones de investigación del Congreso Federal norteamericano y su refinada capacidad de controlar al Gobierno. Además, el funcionamiento paralelo de distintas comisiones permite dedicar mayor tiempo de estudio a la fiscalización de asuntos que, por su entidad, no merecen ser tratados por el pleno.

Las atribuciones de control que suelen tener mayor relevancia práctica son las que son ejercidas de manera regular y no exigen el apoyo de la mayoría. Entre éstas, se encuentran las preguntas orales e interpelaciones, que en la práctica deben cumplir varios requisitos para convertirse en instrumentos efectivos de control. Tales exigencias también son aplicables a las comparecencias del jefe de gobierno y miembros del gabinete ante el pleno y comisiones. La primera es la oportunidad, pues la explicación del gobierno debe ser presentada en el parlamento en el momento adecuado. Observemos que las tardías respuestas que ofrecen algunos gobiernos europeos en el parlamento constituyen una causa del desprestigio de la institución. En segundo lugar, las comparecencias debieran ser regulares, al modo de los question time que existen en Gran Bretaña y Alemania. La cuenta pública de la gestión gubernamental debe convertirse en una actividad periódica, pues de otro modo el tiempo diluye la responsabilidad política.

Las preguntas o requerimientos escritos de información también pueden servir como aporte significativo a las tareas de control. Para estos efectos, es conveniente garantizar un plazo razonable de respuesta lo que, de ordinario, exige establecer un número máximo de preguntas por mes y diputado (como en el Bundestag). Esta restricción impide que la labor del ejecutivo sea obstruida por un número excesivo de preguntas parlamentarias.

Por último, cabría intentar revitalizar la función legislativa y presupuestaria como procedimiento de control. La segunda, muy especialmente, podría servir de base para una rigurosa evaluación anual de la gestión gubernamental. 
Como señalamos antes, en el presidencialismo, el funcionamiento de los instrumentos de control no es el mismo que en los parlamentarismos. La función legislativa es uno de los pilares de la fiscalización y de ahí que los ejecutivos hayan desarrollado diversos procedimientos para crear normas generales sin el consentimiento de la asamblea. En materia presupuestaria, las facultades del gobierno han sido incrementadas por medio de privilegios y por la enorme distancia que existe en la capacidad de planificación presupuestaria de los distintos ministerios y la capacidad de análisis del parlamento. En nuestra opinión, el perfeccionamiento del control exige que ambas competencias retomen su cauce tradicional, lo que puede lograrse disminuyendo las prerrogativas del gobierno y aumentando la participación de los parlamentarios en el proceso legislativo.

En relación con otras competencias de control, queda todavía un vasto campo por desarrollar en materia de comisiones de investigación, cuya regulación todavía sigue siendo poco satisfactoria en muchos países de Iberoamerica. En términos generales, el fortalecimiento de las comisiones es otra tarea que debiera redundar en una mejor fiscalización de las asambleas. Un buen sistema de comisiones puede servir para perfeccionar el control sobre una organización pública cada vez más intrincada.

No debiera descartarse la creación o reimplantación de procedimientos de control típicos del parlamentarismo y que no parecen incompatibles con la separación de poderes. Así, por ejemplo, la formulación de preguntas o la comparecencia regular de miembros del gabinete $\longrightarrow$ de otros miembros de gobierno en comisión - constituye un mecanismo fiscalizador admisible en todo régimen de gobierno. De hecho, el bearing norteamericano es precisamente un tipo de comparecencia pública ante comisión, que no se diferencia de un procedimiento parlamentarista. En este campo la ausencia de la censura, una herramienta más teórica que práctica, puede subsanarse con la posibilidad de sanción, también teórica o práctica, mediante el rechazo de proyectos de ley promovidos por el ejecutivo.

Antes terminar, debemos observar la importancia de dos factores para el ejercicio de la función fiscalizadora. El primero es el de la asesoría parlamentaria. EI parlamento necesita de órganos técnicos que ilustren a sus miembros acerca de los asuntos sometidos a examen. Sin el respaldo de especialistas, el ejecutivo siempre puede intentar evadir su responsabilidad política argumentando con razones técnicas que no podrán ser rebatidas por los parlamentarios. Una asamblea que disponga de personal asesor suficiente podrá evaluar de mejor manera la gestión gubernamental, incluso en campos que se entienden dominados por disciplinas muy técnicas. En América, el Congreso Federal norteamericano y el brasileño disponen del apoyo de grandes organizaciones de asesoría profesional. Tal apoyo, todavía incipiente en algunos parlamentos europeos y americanos, es un elemento básico para adaptar la fiscalización a las demandas del sistema político actual. 
El segundo factor importante es la publicidad. Las actuaciones del parlamento, tanto legislativas y de fiscalización, deben ser siempre públicas. Y no sólo eso: es un deber político asociado a la función representativa el buscar las vías para que este carácter público no sea sólo una categoría formal, apoyada exclusivamente en la posibilidad de asistir a las sesiones o en diarios de sesiones. El parlamento tiene que explorar nuevos medios para comunicarse con los representados y establecer un vínculo sólido que dé sentido a la institución dentro del sistema político. De otro modo, el parlamento seguírá siendo una "casa sin ventanas" que no mira hacia la sociedad y que no es vista por ésta, condenada a cumplir una función secundaria dentro de los poderes públicos.

\section{BIBLIOGRAFÍA}

-BAAKIINI, Abdo, "Legislative Reforms in the Brazilian Chamber of Deputies 1964-1975" en BAAKI.INI, Abdo y HFAPHIIY, James, Comparative Legislative Reforms and Innovations, Albany, Comparative Development Studies Center-State University of New York, 1977.

-BIRCII, Anthony, The British System of Government, Londres, Routledge, 1993 (9a ed.).

-BRYCE, Lord, "The decline of legislatures" en NORTON, Philip (ed.), Legislatures, Oxford, Oxford UP, 1992.

-CEA EGAÑA, José Luis, "Sobre el principio de legalidad presupuestaria" en Revista Chilena de Derecho 3, vol. 19, Santiago, PUC, 1992.

-CILGNOLLAUd, Dominique y QUERMONNE, Jean-Louis, Le gouvernement de la France sous la Ve. République, París, Fayard, 1996 (nueva ed.).

-DILLA SALA, Vincent, "The Italian Parliament: Chambers in a Crumbling House" en NORTON, Philip, Parliaments and Governments in Western Europe, Londres, Frank Cass, 1998.

-DÖRING, Herbert, Parliaments and Majority Rule in Western Europe, Frankfurt, Campus Verlag/St. Martin's Press, 1995.

-FAusto, Boris, História do Brasil, São Paulo, Editora da Universidade de São Paulo-Fundação para o Desenvolvimento da Educação, 2001 ( $9^{\mathrm{a}}$. ed.).

-Griffith, J.A.G.; RYle, Michael; WheEler-BoOTH, M.A.J., Parliament: Functions, Practice and Procedures, Londres, Sweet \& Maxwell, 1997 (reimpresión).

-HuGHFS, Steven y MijesKI, Kenneth, Legislative-Executive Policy-Making: The Cases of Chile and Costa Rica, Beverly Hills, Sage, 1973.

-MAITlaND, F.W., The Constitutional History of England, Cambridge, Cambridge University Press, 1926.

-Miny, Yves, Government and Politics in Western Europe, Oxford, Oxford UP, 1993 (2 ed.). 
-MOLintelit, Guillermo, "Una cronología de los períodos de sesiones del Congreso argentino (1854-1986)" en Revista de Derecho Parlamentario 3, Buenos Aires, Dirección de Información Parlamentaria-Cámara de Diputados, 1991.

-Nogueira Alcalá, Humberto, Análisis critico del presidencialismo y consideraciones sobre una alternativa de régimen-semipresidencial para Chile, Santiago, Instituto Chileno de Estudios Humanísticos, 1986.

-NORTON, Philip, "Nascent Institutionalisation: Committees in the British Parliament" en LONGLEY, Lawrence y DAVIDSON, Roger, The Nem Roles of Parliamentary Committees, Londres, Frank Cass, 1998.

-O'HALPIN, Eunan, "A Changing Relationship? Parliament and Government in Ireland" en NORTON, Philip, Parlaments and Governments in Western Europe, Londres, Frank Cass, 1998.

-PACTET, Pierre, Institutions politiques. Droit constitutionnel, París, Armand Colin, 1999 (18 ed. actualizada hasta agosto de 1999).

-PÉREZ ANTÓN, Romeo, "Poder Legislativo y ordenamiento constitucional: el caso uruguayo" en CABALLLRo CARRIZOSA, Esteban y VIAL, Alejandto (eds.), Poder Legislativo en el Cono Sur, vol. I, Asunción, Centro de Estudios Democráticos, 1994, 109-123.

-PYPER, Robert, "Ministerial Responsability and Next Steps Agencies" en GIDDings, Philip (ed.), Parliamentary Accountability, Hampshire, Macmillan Press, 1995.

-Rımírez Altamirano, Marina, Manual de Procedimientos Legislativos, San José, Investigaciones Jurídicas S.A., 1994.

-SIIAW, Malcolm, "Parliamentary Committees: A Global Perspective" en LONGLlEY, Lawrence D. y DAVIDSON, Roger H., The Nen Roles of Parliamentary Committees, Frank Cass, 1998, 225-251.

-TAPIA VALDÉS, Jorge, "Funciones y atribuciones del parlamento entre 1960 y 1990" en BERTELSEN REPETTO, Raúl; CEA EgAÑA, José Luis; Cumplido Cereceda, Francisco; Nogueira Alcalá, Humberto; Oetckiers CAMUS, Osvaldo; TApin Valdés, Jorge; Vergara BlanCO, Alejandro, Diagnóstico Histórico Jurídico del Poder Legislativo en Chile 1960-1990, Valparaíso, Centro de Estudios y Asistencia Legislativa Universidad Católica de Valparaíso, 1993.

-THWATtes REY, Mabel, "Apuntes para pensar la modernización del Parlamento argentino" en Primer Congreso Internacional de Modernización Parlamentaria, Documentos y Conclusiones, Tomo II, Buenos Aires, Congreso de la Nación Argentina, 1991.

-Turpin, Dominique, Le régime parlementaire, París, Dalloz, 1997.

-Vallinzuela, Arturo, "Partidos políticos y crisis presídencial en Chile: proposición para un gobierno parlamentario" en GODOY ARCAYA, Oscar (ed.), Hacia una demacracia moderna. La opción parlamentaria, Santiago, Ediciones Universidad Católica, 1990. 
-WHEARE, Kenneth C., Legislatures, Londres, Oxford University Press, 1963. -Young, Roland, The British Parliament, Evanston, Northwestern University Press, 1962. 